\title{
"TODAS TUS FUERZAS, TUS FACULTADES, TUS VIRTUDES ESTÁN INTACTAS": CRIMINALES ENTRE DOS PARADIGMAS EN HIJO DE LADRÓN
}

\author{
Diego Leiva Quilabrán \\ Universidad de Chile \\ Santiago, Chile \\ diego.leiva@ug.uchile.cl
}

En su ensayo "Algo sobre Hijo de ladrón", incluido en Antología autobiográfica (1962), Manuel Rojas describe el inicio de la gestación de su novela Hijo de ladrón:

Solo pretendía aprovechar algunas experiencias propias y otras ajenas, describir seres y ambientes, expresar, como pudiera los sentimientos o las reflexiones que todo ello podía producir.... No todos los personajes habían existido al mismo tiempo, no; habían existido, o existían aún ... Con los hechos ocurría igual cosa.... Los personajes tuvieron que resucitar o morir, y los hechos, retroceder y avanzar. El que mandaba era yo, aunque no estaba seguro de lo que había que hacer (366-7).

Esa declaración contiene los elementos que funcionarán como pie para estos apuntes. Primero, Rojas plantea que la primera novela de la tetralogía de Aniceto Hevia fue el resultado del procesamiento de experiencias personales, sobre las que se intervino deliberadamente. Si esa intervención fue más o menos pensada, si fue hecha con mayor o menor seguridad de lo que "había que hacer", eso no es lo que nos compete. Más bien, el asunto aquí será la distancia que hay entre algunos de los hechos procesados y el modo en que aparecen en la ficción. Al hablar de "algunos de los hechos" me refiero particularmente a la presencia, acción y reacción de sujetos criminales, irremediablemente condicionados por las vicisitudes históricas del tiempo 
en que se ambienta la historia. Por otra parte, con el "modo de aparición" hago referencia a los juicios y relaciones en las que se ven envueltos, desde el punto de vista del narrador. En palabras del investigador Ignacio Álvarez,

la relación entre el nuevo paradigma narrativo y el género novela autobiográfica es estrecha y problemática. Tensiona, por un lado, los polos referencial y ficticio, pues lo que se narra en esas novelas debe ser entendido como la información referida a la realidad exterior y al mismo tiempo como relato autorizado para gozar de todas las libertades que normalmente les concedemos a los textos de imaginación: Aniceto Hevia es el joven Rojas aunque, por supuesto, no lo sea en absoluto (103).

En el fondo, no estoy más que poniendo sobre la mesa aquel rasgo determinante de la novela moderna que comentó Wolfgang Kayser: la incongruencia entre los medios directos e indirectos de la representación y, con ello, la posibilidad de presentar de modos diferentes y simultáneos las figuras en escena (65-6) ${ }^{1}$. En esta incongruencia se está jugando la legitimidad de las subjetividades criminales o la falta de ella. En Hijo de ladrón se entrelazan dos visiones en cuyo interregno se producen algunas inestabilidades.

Por un lado, el sujeto criminal, en el tiempo de lo narrado, es objeto de determinaciones forzosas y arbitrarias en escenas específicas, a las que reaccionan de maneras particulares. La infancia del narrador-protagonista-autor transcurre en años que bordean el cambio de siglo, momento crítico para el proyecto oligárquico de los relativamente jóvenes Estados latinoamericanos. Durante esos mismos años, los sujetos marginalizados, excluidos del progreso moderno y marcados por la cuestión social, fueron tratados por los Estados en consonancia con formulaciones científicas o pseudocientíficas que tuvieron como objetivo restringir su entrada al campo de la acción política.

[A] partir de un juego de oposiciones binarias entre valores y conductas consideradas limpias, sanas y honestas, y las definidas como inmorales, subversivas y peligrosas, se trataba de establecer

1 Siendo Hijo de ladrón una novela que se encuentra en el horizonte estético de la vanguardia, es correcto asegurar que uno de sus rasgos definitorios es la incoherencia y no la incongruencia. A sabiendas de ello, la propuesta aquí elaborada reposa en aquellos momentos en que se advierten residuales de la novela moderna, es decir, cuando la narración pasa por remansos narrativos relativamente coherentes. 
con claridad la frontera entre la normalidad, que correspondía a los valores burgueses y lo patológico, perteneciente al mundo del desorden (Campos 23)

Por otro lado, el narrador, ojo que mira, está alejado del tiempo de los hechos, intentando instalar una ética y proponiendo una vía política de comunidad que supere esas determinaciones. No solo está queriendo tomar toda la distancia posible de las formulaciones de comunidad que constituyeron las clases dirigentes durante un siglo, en el plano político, sino que también está empeñando en tomar distancia de la narrativa criollista que imperó durante las primeras décadas del siglo XX, en el plano estético, integrando técnicas literarias de las vanguardias. Para Cedomil Goic, justamente, Hijo de ladrón implicó "un cambio absoluto en la aprehensión del mundo por parte de un nuevo tipo de narrador, descreído y desconfiado de los saberes positivos que agotaron las posibilidades de la escritura en la generación criollista" (129).

No obstante, como punto medio a estos dos polos, hay que considerar también que, tal como señala Jaime Concha, el ladrón es un paradigma narrativo por sí solo, pertenece a la memoria oral, artística y moral, y es plasmado abundantemente en distintos medios y desde distintas perspectivas durante la primera mitad del siglo XX ("El otro tiempo perdido" 229). Así, a medias formados en el imaginario rojiano por el contacto directo durante su vida y a medias como recurso literario de larga data en un uso particular, es que se puede obtener una imagen medianamente clara de la base del tratamiento del delito en Hijo de ladrón.

Josefina Ludmer valora el delito como un instrumento crítico en el que se puede leer un diálogo entre la ficción y la realidad. Las ficciones en las que hay un contenido delictual pueden tratarse como "ficciones de identidad cultural", pues el delito traza una línea al interior de una cultura o la separa de otra (16-7). Al hablar de la narrativa que acompañó a la consolidación del Estado liberal argentino a partir de 1880, agrega la teórica argentina que los escribientes de ese proyecto político legitimaron sus subjetividades tanto dentro como fuera de la ficción. Por eso sería tan relevante que autobiografías reales en forma de recuerdos (como Juvenilia de Miguel Cané) o autobiografías ficcionales (como La gran aldea de Lucio V. Mansilla) tomaran un lugar preponderante en la literatura nacional.

En ese sentido, una novela como Hijo de ladrón, escrita hacia 1950 y que relata hechos de las primeras décadas del siglo XX, a nivel de la forma y del contenido, puede leerse en el encuentro de dos paradigmas para la comprensión 
del hecho criminal que se interrelacionan en múltiples discursos durante la narración. Esos paradigmas marcan también la condición del narrador socialmente marginal en el enunciado e integrado en el momento en que enuncia (Álvarez 105). Además, es posible asegurar que en ese juego entre la ficción y la autobiografía se establecen posiciones relativas que dan lugar a formas de legitimación de nuevos sujetos en el camino de la modernización y en su relación con las fuerzas disciplinares del Estado.

Estos breves apuntes no tienen otro objetivo más que revisar de modo breve algunos de los nudos en que la cuestión de la criminalidad, en pleno período de modernización, emerge en la primera novela de la tetralogía de Aniceto Hevia. A través de la selección y análisis de fragmentos específicos del texto, apunto a delimitar algunos segmentos de información en que la frontera del delito emerge como indicio. Para ello, considero la valía de formas como la autobiografía novelada y la ficción, cuya relación a lo largo de la tetralogía "[s]erá a veces bifurcación, otras veces antítesis; una vez una gran tetralogía novelada, otra vez ficción con elementos secundariamente novelescos" (Concha, "Los primeros cuentos de Manuel Rojas" 222).

Será posible advertir en el desarrollo de estas páginas cómo se mueve Rojas en relación con su identidad cultural, para transitar por el límite cultural del crimen, a la hora de ser juzgado y juzgar. Esto último entronca con las reflexiones de Lorena Ubilla, que llamó "sujetos fronterizos" a esa colectividad de marginales que, dada su condición, podían transitar entre diversos órdenes, mundos y prácticas culturales (1).

\section{LA SALIDA DESDE EL LÉXICO: DE RATAS A LADRONES}

El estudio filológico e interpretativo de Barrera, en que se comparan de manera general los dos mecanoscritos previos a la publicación de la primera edición de Hijo de ladrón (Nascimento, 1951) y luego esta con la última revisada por el autor (Obras completas, Zig-Zag, 1961), dio cuenta de que el proyecto narrativo de Rojas tiene por voluntad general la universalización de lo narrado, buscando ampliar su legibilidad y aumentar su traductibilidad (26). Habiendo avanzando un poco más en la edición crítica de la novela, en un equipo del que tengo la fortuna de formar parte, y habiéndose incluido una revisión pormenorizada de los mecanoscritos en el cotejo, creo que puedo agregar unas cuantas puntualizaciones que siguen la tesis de Barrera y que se aplican aquí a la cuestión criminal. 
Este apartado tiene su fuente principal en cierta variante léxica que aparece durante la historia de Victoriano, el vigilante de la estación, quien fuera "durante años la pesadilla de los ladrones de carteras" (Hijo de ladrón 49), y que luego se verá en posición de cómplice del latrocinio para finalmente ser despedido del servicio al atrapársele con billetes marcados. Según Berta López, esta historia define el estatuto de la ley y su transgresión, asumiendo que la posición de servidor de la ley no constituye de por sí una conducta intachable (298).

Más allá del jaque a lo intachable y a los caracteres inamovibles, que refuerza lo señalado en la sección anterior, la reflexión aquí planteada va en línea, como se dijo, de un uso léxico particular. Tómese como referencia el siguiente fragmento:

Víctor Rey, gran rata, logró entrar una vez y salir dos [de la estación vigilada por Victoriano]; pero no parecía un señor: parecía un príncipe; se cambiaba ropa dos veces al día y las uñas le relucían como lunas. Salió retratado en una revista francesa; alto, moreno, de bigotito y pelo rizado, un poco gordo y de frente muy alta; parecía tan ladrón como yo parezco fiscal de la Corte de Apelaciones. Conocía a Victoriano como a sus bolsillos -antes de venir se informó- y la primera vez salió de la estación con veinticinco mil pesos y varios cheques. Era el tren de los estancieros. Victoriano recibió la noticia como un joyero recibe una pedrada en el escaparate. Ningún carterista conocido ni ningún sospechoso entró aquel día a la estación ni fue visto en un kilómetro a la redonda (Hijo de ladrón 50; énfasis mío).

En los mecanoscritos fechados en 1950 y 1951 y titulados Tiempo irremediable, las tres palabras destacadas son reemplazadas por una sola: "punga". Este fenómeno se repite a lo largo del capítulo. En una pesquisa rápida, podemos comprobar que "punga" refiere a un tipo específico de robo, el que actualmente referiríamos como "hurto", pero también como apócope de "punguista", aquel ladrón que practica el hurto. Eusebio Gómez, criminalista argentino de principios del siglo XX, en su texto La mala vida en Buenos Aires, describe al punguista citando a su colega español Rafael Salillas y Pinzano: "Es el que con apropiada táctica y estrategia, y valiéndose de su especial habilidad manual, especificada en dos dedos de la mano derecha (específicamente el pulgar y el índice) sustrae hábilmente del bolsillo en que un propietario los lleva ó [sic] de la prenda en que están sujetos, los relojes, carteras y alfileres" (cit. en Gómez 77). 
Es acertado señalar que el cambio de "punga" por "rata", "ladrón" o "carterista" ayuda a la legibilidad universal. Sin embargo, no se puede dejar de reconocer que al ganar riqueza y variabilidad léxica, se pierde un referente preciso, cuyo nombramiento es apropiado usar cuando hay o bien una continuidad con la comunidad jergal del receptor o bien cuando el aparataje técnico detrás de la enunciación del discurso lo permita; es decir, de par a par en diálogo abierto con su destinatario o como un observador especializado. El cambio lexical es explicable en la medida en que la narración con pretensión universal gana en en comprensibilidad y traductibilidad fuera de la comunidad lingüística chileno-argentina, pero junto con el localismo sacrificado se desvanece una cercanía dialectal o una objetualización estigmatizadora que no es permisible para el letrado integrado de mediados de siglo.

La existencia de dos paradigmas en la conjunción entre la narración y lo narrado no se reduce a una doble percepción coordinada. Si se amplía el campo visual, es posible hablar de puntos de vista respecto de una comunidad: en lo narrado, los objetos intentan aprehenderse desde dentro de una sociabilidad marginada; durante el acto de narrar, Aniceto Hevia/Manuel Rojas se encuentra integrado a un aparato cultural que está lejos de llamarse marginal y dentro del cual puede desarrollar un proyecto individual apartado del positivismo tainiano.

Sacar la voz "punga" puede ser interpretado como una solución conveniente. Dentro de la evolución del texto, es un rechazo al determinismo léxico propio del criollismo para buscar voces más universalmente legibles. No obstante, ese dato jergal también puede ser entendido sintomáticamente como un extrañamiento autorial, un retroceso en el conocimiento y el reconocimiento de voces populares que lo acercarían a quien ya no puede sino mirar de lejos, o al menos desde más distancia que en su juventud, en que los pungas pululaban por su vida como los compañeros de habitación, ignotos y desconectados. Esta lejanía no implicaría un rechazo directo, pues hay que tener presente el trasfondo humanista que la formación anarquista de Rojas presupone: se diferencia de un colectivo, pero su visión sobre él trasciende al determinismo lexical y socio-ambiental que se sostenía a comienzos del siglo.

No es mi objetivo determinar la cualidad ética del narrador o condenar su "distanciamiento". Como señala David Barrera, es plausible sostener que, en líneas generales, los cambios (lineales, pero también con algunas idas y vueltas) están basados en estrategias de legitimación al interior de un campo literario moderno, con sus jerarquías instituidas (4). Observar un detalle como el aquí comentado permite advertir el grado de precisión y cuidado con el 
que Hijo de ladrón fue pensado, de forma absolutamente consciente en su evolución prerredaccional y redaccional, lo que seguramente será motivo de nuevas y sucesivas investigaciones.

\section{ELIMINAR LAS DETERMINACIONES}

En este punto vale la pena ampliar la reflexión. Si la sustitución sistemática de "punga" puede leerse como un cambio de posición tanto respecto del objeto como de la institucionalidad que lo observa y mide, hay otras variantes, de mayor extensión, que van en la misma línea.

A propósito de la superación de presupuestos deterministas al interior de Hijo de ladrón, se ha señalado que en la novela hay una deliberada actitud de terminar con la preeminencia de esos presupuestos, vinculados entre otras cosas al medio, presente en la narrativa decimonónica; además, para lograr aquello Rojas se vale de las catálisis narrativas, ya que es en los detalles en donde más se pone en entredicho los postulados de raza, medio y circunstancias históricas (Fuentes Retamal 203). Sobre este punto, el de las dinámicas de sociabilidad en la masa marginal, Manuel Rojas diría en 1972 que este lumpen "es un producto de la sociedad, de la organización de la sociedad" y que "[e]n el medio del lumpen se lleva a cabo la más primitiva y brutal lucha por la existencia [...] son hijos del hambre" ("Variedades de lumpen" 266). De esto se puede colegir la intuición del Rojas tardío sobre el origen sistémico de un tipo social que, producto del hambre, sobrevive de maneras incivilizadas. Si se considera la cita sobre el lumpen como un punto de llegada en la trayectoria intelectual del autor, un par de movimientos en la evolución del texto cobran sentido.

Al decir de Marx, "no es la conciencia de los hombres lo que determina su ser, sino, por el contrario, es su existencia social lo que determina su conciencia" (5). La narrativa rojiana presenta subjetividades completamente abiertas al devenir de esa existencia social, abiertas en tanto permiten un contacto transversal, a partir del propio narrador, quien sustenta juicios sobre su exposición al mundo y sus relaciones más o menos estables con otros individuos o grupos. Es por eso que un fragmento como el siguiente, que figura en el mecanoscrito de $1950 \mathrm{y}$, tachado completo en el de 1951, no llegaría siquiera a la primera edición: 
Los patrones aprovechaban la abundancia y un día casi acogoto a uno; me quedaban diez centavos y compré el diario para ver los avisos: "Necesito joven..." Yo era joven, pero el lugar estaba muy lejos, al otro extremo de la ciudad; allá me fuí, gastando mis últimos diez centavos, con la esperanza y la seguridad de ser el primero en llegar ... fui [sic] el primero en llegar y cualquier hombre con dos brazos, y aun con uno, podía hacer el trabajo ...; pero algo hubo que no le gustó al patrón, la forma de mis orejas, el color de mis ojos, el corte de mi chaleco, qué sé yo, el caso es que me dijo que el puesto ya estaba ocupado; le contesté que no podía ser: nadie más que yo había llegado hasta ese momento; lo sabía; entonces, descubierto, mintió, diciendo que lo había pensado mejor y que no iba a tomar empleado. Me dió rabia: era un individuo gordo, bajo, con el pelo tieso y cortado en forma cuadrada; estaba en camiseta detrás de un escritorio con muestras de mercaderías y chorreado de café y de tinta; me fuí sobre él y le pregunté si creía que la gente experimentaba algún placer en venir a contemplar su camiseta o su escritorio, que había gastado mis últimos diez centavos en comprar el diario y llegar hasta allí, despreciando otros avisos; que era un abusador y que si no me daba el empleo debía indemnizarme; de otro modo, procedería en justicia rápida. El tipo, más asustado que una lagartija, abrió tamaños ojos y se quedó mirando mis manos, creyendo talvez que de pronto me llevaría una a la cintura, sacaría un cuchillo y le rebanaría el mugriento pescuezo. Era tiempo de malevos en Buenos Aires. Por fin, sacando la respiración, que con el susto se le había metido para adentro, me preguntó que con cuánto me quedaría tranquilo: “¡Cinco pesos!”, le grité, estirando una mano y reteniendo, al mismo tiempo, la risa y la cachetada. Sacó algunos arrugados billetes de a peso, tan sucios como él, y me apoderé de ellos, marchándome antes de que reaccionara y antes de que me diera vergüenza; qué diablos, hay gente que quisiera abusar de uno cuando lo ve derrotado... (Tiempo irremediable 68-9).

Esta parte corresponde a un fragmento hacia el final del relato de su vida que le ofrece el vagabundo de las tortugas a Aniceto. En función del personaje, la escena no corresponde a su actitud en general tranquila y templada. En relación con el tono de la novela, Barrera señala que esta eliminación se condice con una excesiva atención a los particulares de la experiencia, a la puerta que abre a la violencia como forma de abordar un conflicto político, posibilidad disruptiva para un camino formativo como el de Aniceto (37). En la línea de estos apuntes, quisiera agregar que justamente esta disrupción que no llega a la versión édita establece particulares de la experiencia a través del delito. 
Es el delito lo que mueve en el fragmento eliminado una determinación más cercana al criollismo. Esto supondría una oposición cerrada de subjetividades: se miran como extraños radicales motivados afectivamente -el patrón por el desprecio, el trabajador por la rabia-; están separados por el escritorio como una barrera de clase, el sitio propio y fijo del patrón contra la movilidad de quien pulula buscando trabajo; finalmente, solo la agresión oblitera esa línea imaginaria. Esta escena contradice la perspectiva autorial de hablar de sujetos cuyas condiciones materiales han de construirlos como subjetividades abiertas, cambiantes, dialogantes, que van de un lado a otro, a saber, subjetividades fronterizas. Esta última forma de explorar el tipo social, menos universal y menos abierta, es la que Rojas descarta. Rojas avanza hacia juicios sobre la transitoriedad en una acumulación reflexiva de su experiencia, lo que a largo plazo le permite a su protagonista una mejor comprensión del mundo hasta alcanzar su estado de madurez. Marcas de esta apertura a la experiencia y a la transformación subjetiva pueden hallarse en otros momento de la novela. Dice el narrador sobre su primera estadía en la cárcel, cuando era un niño:

Una noche en una comisaría y un día, o unas horas nada más, en el calabozo de un Departamento de Policía, junto a unos hombres desconocidos, era toda mi nueva experiencia y, sin embargo, era suficiente. En adelante nada me sorprendería y todo lo comprendería, por lo menos en los asuntos que a mí y a los míos concernieran (Hijo de ladrón 40).

Ya más cerca del fin de la novela, Aniceto tiene impresiones sobre la cerrazón que manifiesta Cristián Ardiles al otro, a diferencia de la apertura que manifiesta Echeverría.

No llegué a saber, por aquellos días, lo que había dentro de Cristián y quizá no llegaría a saberlo nunca. Viviendo a su lado, en su contorno, sentí que lo rodeaba una atmósfera de una densidad impenetrable para la simple mirada o la simple cercanía. No irradiaba nada que pudiera ser comprendido de un modo inteligente y no supe si lo que los demás irradiaban, El Filósofo u otros, lo tocaba. (337)

En este punto, cerrazón es sinónimo de ininteligibilidad.

Durante la escena del altercado entre el hombre de las tortugas y el patrón, el delito es el único mecanismo que pone en contacto a dos tipos de manera literal -metonímicamente directa, si se quiere, pues el individuo aparece por su grupo-, y deviene en la anulación del polo agresivo, en la supresión 
del delincuente y, por ende, en el fracaso de una integración dialogante. Si tuviera que comparar esta situación con el paradigma criollista, bien vendría al caso recordar el texto "El aspado" de Mariano Latorre, que comienza con un bandido herido huyendo de la partida policial y termina con un acto sacrificial del mismo, entregado a la penitencia religiosa y a la purga de sus delitos. Para que el sujeto criminal no replique los caminos de la anulación o el sacrificio, el narrador debe asirlo de otra forma, esto es, como lo que acá se ha llamado figura abierta: criminal, pero como estatus transitorio y con la posibilidad cierta (aunque potencialmente negada por sí mismo) del encuentro con otro, o de movilizarse hacia una ética del trabajo.

Otra señal del camino de recortes ideológicos es un cambio realizado tardíamente, pues el fragmento permanece al menos hasta la edición de Zig-Zag de 1958, con leves variaciones desde los mecanoscritos. En esa edición puede leerse:

Odiaba a esos individuos que viven en los alrededores de las ciudades, en terrenos eriazos, bajo armazones de latas y de sacos rodeados de gatos, perros y pulgas; me parecían hombres sórdidos sin atmósfera propia o con una de perros y gatos; seres alumbrados por una imaginación tan obscura como sus pocilgas y que no encuentran nada más interesante que imitar a otros hombres sus casas, sus comodidades, rodeándose para ello de animales repelentes, gatos enfermos, perros sarnosos; muchos se creen dueños de los terrenos en que viven y ahuyentan a los niños que van a jugar sobre el pasto, cerca de sus pestosos ranchos; prefería los vagabundos sin casa. Pero éstas son tortugas pequeñas, torpes y graciosas al mismo tiempo, color tierra; caben las dos en una mano y se desplazan como terrones sobre el húmedo pasto fluvial. Le dan prestancia, originalidad, distinción. ¿Por qué las lleva? No podrá comérselas en caso de necesidad ni le servirán de guardaespaldas o de cómplices en ninguna pilatunada. Su ventaja es su pequeñez (Hijo de ladrón [1958] 52-3).

Este extracto forma parte de la primera descripción que el narrador realiza del hombre de las tortugas. La figura del recién conocido es radicalmente opuesta a otras que ha visto, se intuye, no tan solo en lo narrado, sino también por su trayectoria vital de observación y comentario. El narrador mira a este recién conocido, pero como en un molde vaciado, también ve su opuesto social: una continuidad en la marginalidad, pero una oposición en su actitud vital. Se explica la posibilidad de establecer una comunidad transitoria con este nuevo amigo argumentando su actitud reposada y también aquello que 
no es: no se parece a las bestias, no tiene una contigüidad con un mundo bajo descrito con una tendencia naturalista. No imita comportamientos, y si no imita, se concluye que puede producirlos de manera original, auténtica.

Tanto la escena en que golpea al patrón como esta comparación, que terminan borradas de la edición definitiva, son señales de la consciente delimitación de una figura que sirve de modelo reflexivo y de ejemplo vital en el camino formativo de Aniceto. Es un sujeto al que no se le puede permitir, en la lógica que busca trazar el narrador-autor, caer en el delito como mecanismo de relación, y no se le permite porque su subjetividad, su modo de ver, no se ha ocluido al otro. No siguen ni el rumbo del criminal popular del naturalismo ni los determinismos sociales del ambiente. Es un sujeto completamente en movimiento, objetiva y subjetivamente; tan en movimiento, de hecho, que terminará por alejarse del protagonista para seguir su viaje.

\section{JERARQUÍAS Y ESPECIALIDADES}

La cuestión criminal en Hijo de ladrón se juega no solo en detalles léxicos y en el rechazo de estereotipos oxidados, sino además en otro elemento determinante: la posibilidad de que desde sus prácticas se organice el mundo y una serie de conductas que alejan al criminal de la simple barbarie, para ponerlo en un rumbo de modernización paralela, subsumida en el crecimiento de las grandes urbes.

La pieza clave en este punto es Pedro El Mulato. Amigo del padre del narrador y conocido de su madre, este personaje visita la casa familiar y permanece allí. A propósito de su presencia y de las historias que le cuenta a los niños sobre su oficio, el narrador señala:

Con los días llegaríamos a saber que Pedro El Mulato no había robado en su vida ni siquiera un pañuelo o un sombrero, pero que vivía del robo, aunque del robo de los demás. Este hombre, inocente y tímido en algunos sentidos, friolento y perezoso, sentía por los ladrones una admiración y un amor que nada ni nadie fue capaz de apagar nunca, ni aun la cárcel, ni aun la miseria, ni aun los castigos. Incapaz de robar, favorecía el robo, suministrando a los ladrones los datos que conseguía. La policía, después de años, terminó por soportarlo, considerándole como un personaje de la vida delictuosa y de quien, como de todos los personajes, no se podía prescindir así como así. Era inútil interrogarlo: lo ignoraba todo, aunque todos estaban enterados 
de que El Mulato Pedro sabía más que toda la policía y el gremio de ladrones juntos. Cuanta rata de categoría entraba a Brasil o salía de él sabía quién era Pedro, qué podía esperar de él, y él, por su parte, estaba informado de quién llegaba y quién se iba, qué hacía, qué iba a hacer y qué había hecho (Hijo de ladrón 251-2).

Siendo una figura lateral en el circuito criminal, Pedro El Mulato toma un rol fundamental al momento de que podamos observar, como lectores, un esquema paralelo. Este personaje pertenece a uno de los últimos escalafones del delito, pero resulta absolutamente necesario en la ejecución y posterior bloqueo de las indagaciones. Su incapacidad para el robo es el reverso perfecto de la capacidad absoluta, de la técnica delicada que hace de la mano de El Gallego una ganzúa. No obstante, esa diferencia de habilidades deviene en complementariedad, en distribución del trabajo en el circuito de producción del delito. En el fondo, se replican estructuras basadas en una razón instrumental y en la especialización del trabajo. Desde este punto de vista no aparecería algo tal como la barbarie absoluta en el delito; el circuito criminal es capaz de producir sus propios razonamientos, establecer sus redes de trabajo y operar de manera efectiva.

Esta distribución racional se presenta, además, como jerarquizada en torno a destrezas naturales. Se dice en páginas siguientes que "hay [gente] que fracasa como ladrón y debe contentarse con ser cualquiera otra cosa más modesta, encubridor, por ejemplo, como era Pedro El Mulato, o comprador y vendedor de objetos robados o, por oposición policía o soplón" (256). Al ejecutor principal, centro del hecho criminal, se le opone un desgranado de funciones en red que sostienen los eventos del encubrimiento o la circulación de mercancías "desviadas", por decirlo eufemísticamente.

Junto con la distribución anterior arriba-abajo, funciona otra, que podría nombrarse como de lado y lado. No tiene como criterio la centralidad o la funcionalidad en la comisión de delitos, sino que se sustenta en un cuadro ético, marcado por una particularización de la mirada. El conjunto de sujetos de una ética degradada se suscita en momentos de escaso detalle sobre la masa, mientras que cuando existe una fijación sobre una personalidad en particular, esta se abre ante el lector como un matizado individuo. Casos de masa son los ratas de la estación vigilada por Victoriano: "El inspector, que en sus primeros años de agente lidió con lo peor del ladronaje, ratas de baja categoría, insolentes y sucios, seguía creyendo que todos eran iguales [...] nunca se le ocurrió conversar con ellos y averiguar qué clase de hombres 
eran" (Hijo de ladrón 55-6). En el momento del motín en Valparaíso, Aniceto recuerda que

Se formaron grupos constituidos por individuos que parecían salidos de las alcantarillas -algunos se habrían podido tomar por enormes ratas-; barbudos, astrosos y de ojos brillantes, llenos de vida, inquietos, que no gritaban ni rompían faroles y que al parecer no sentían odio ni amor por nadie, pero que se apoderaban, con una asombrosa rapidez, casi animal, de cuanto se hallaba al alcance de sus manos (156).

Del lado de un crimen irreflexivo, del que no se produce ni extrae conocimiento sopesado ni experiencia práctica, está la masa de ratas cuyos rasgos principales serían el de ser homogénea y el de tener un apetito voraz, casi animal. Cuando el trabajador policial que ficha al niño Aniceto en su primera ida a la cárcel, habla de que El Gallego era "decente... no un cochino" (44). Por ende, la filiación del narrador se entronca no con el rata, sino con un grupo definido, menor, pero más complejo, en donde caben, además de su progenitor y Pedro El Mulato, personajes como Nicolás, el falsificador de billetes, Victoriano, Víctor Rey, El Manco Arturo, Ipinza y González. Ellos tienen conductas que podrían juzgarse como reflexivas y, por lo tanto, el lector y el narrador en formación los pueden valorar positivamente en su dignidad humana tras conocerlos u oír sus historias. Mirados de manera individual es cuando adquieren su distinción de los otros: ellos se involucran, no depredan, simplemente delinquen con habilidad.

Todos ellos han sido llamados aquí subjetividades abiertas: dialogan y se forman socialmente más allá de sus determinantes sociales, se elevan del suelo, se permiten ser livianos, gráciles, tratables, y no animales salidos de alcantarillas. Tal y como Aniceto en su viaje formativo, han hecho hombres de sí mismos con claridad, en caminos heterogéneos, aun cuando sus vínculos con otros sean demasiado endebles y se hagan, por momentos, por fuera de la ley.

Hasta este punto, se han recorrido distintos caminos modernizadores que recomponen el hecho criminal como objeto y la mirada que se lanza sobre él. Entre otros aspectos destacables de la narrativa rojiana, considero que la desontologización del crimen es un aspecto de particular relevancia. Ser hijo de ladrón no es un estigma, más bien funciona como una puerta para acceder a un interregno. Durante su primera ida a la cárcel, tanto un detenido como el funcionario policial le realizan la misma pregunta al pequeño Aniceto: ¿es él el hijo de El Gallego? De un lado y otro de la frontera de la ley pueden reconocerlo, lo miran con familiaridad. Entre la cercanía radical, 
que determinaría el camino de Aniceto como un ladrón más, y ponerse del lado de la ley y el juicio moral, Hijo de ladrón va mostrando las razones de facto para una tercera mirada: la lejanía respetuosa e inclusiva.

Se ha señalado que Rojas ha de defender su personaje como una muestra de la incapacidad del Estado para asimilar a las capas populares en el proyecto nacional de las capas ilustradas (Amaro y Arecheta 54); también se ha enfatizado que su proyecto narrativo radica en la integración al imaginario nacional de esa clase popular esencialmente abierta sin definirla de una vez y para siempre (Álvarez 107). En estas escasas páginas se ha querido aportar, mediante la relevación del asunto criminal en tres puntos, un material significativo para la definición o indefinición de ese grupo social y para con su disposición en torno a la legalidad y la legitimidad.

Los esfuerzos autoriales de Rojas van encaminados de manera sincrónica, a través de sus personajes en el texto, y diacrónica, mediante las diferentes versiones del mismo, a referir de la manera más adecuada un tipo abierto $\mathrm{y}$, con ello, una necesaria tipología abierta completa de acceder al fenómeno del crimen y la marginalidad en la literatura nacional. En el vitalismo de su personaje-narrador es posible aplicar a sus delincuentes una de las sentencias más íntimas de la novela: "todas tus fuerzas, tus facultades, tus virtudes están intactas y se desarrollarán a su debido tiempo o se han desarrollado" (Hijo de ladrón 138). La pulsión conciliatoria de un nuevo ideal de comunidad nacional del autobiógrafo ficcional debe enfrentarse a cada momento con los fantasmas de sus objetos representados, marginales y criminales, y para ello elige un anarquismo, en su sentido humanista, de base.

\section{BIBLIOGRAFÍA}

Álvarez, Ignacio. "El diagrama de un nuevo pacto". Novela y nación en el siglo XX chileno. Ficción literaria e identidad. Santiago: Ediciones Universidad Alberto Hurtado, 2009. 95-140.

Amaro, Lorena y Ghislaine Arecheta. "Modernización y experiencias en la narrativa chilena de la primera mitad del siglo XX". Confluencia 29.2 (2014): 49-60.

Barrera Fuentes, David. "La prosa nunca está terminada”: análisis de algunas variantes textuales de Hijo de ladrón (1951) de Manuel Rojas. Tesis para optar al grado de Licenciado en Lengua y Literatura Hispánica de Licenciatura. Universidad de Chile, 2019.

Campos, Ricardo. "Locos y criminales. El papel de la ciencia en la configuración del criminal en el siglo XIX". Industria del delito: historias de las ciencias criminológicas en Chile. Eds. Cristián Palacios y César Leyton. Santiago: Ocho Libros, 2014. 11-28. 
Concha, Jaime. "El otro tiempo perdido". Leer a contraluz. Estudios sobre narrativa chilena. De Blest Gana a Varas y Bolaño. Santiago: Ediciones Universidad Alberto Hurtado, 2011. 223-244.

"Los primeros cuentos de Manuel Rojas". Leer a contraluz. Estudios sobre narrativa chilena. De Blest Gana a Varas y Bolaño. Santiago: Ediciones Universidad Alberto Hurtado, 2011. 201-222.

Fuentes Retamal, Pablo. "La mancha indeleble de Aniceto Hevia: determinismo y superación en la tetralogía narrativa de Manuel Rojas". Literatura: teoría, historia, crítica 17.1 (2015): 171-206.

Goic, Cedomil. "Hijo de ladrón". La novela chilena. Los mitos degradados. Santiago: Universitaria, 1970. 124-143.

Gómez, Eusebio. La mala vida en Buenos Aires. Buenos Aires: Ediciones Biblioteca Nacional, 2011.

Kayser, Wolfgang. "Origen y crisis de la novela moderna". Mapocho 2.3 (1965): 58-80.

López, Berta. "El aprendizaje de Aniceto Hevia”. Manuel Rojas: estudios críticos. Eds. Naín Nómez y Emmanuel Tornés Reyes. Santiago: Editorial Universidad de Santiago, 2005. 287-317.

Ludmer, Josefina. "Introducción". El cuerpo del delito. Un manual. Buenos Aires: Eterna Cadencia, 2011. 13-26.

Marx, Karl. "Prólogo". Contribución a la crítica de la economía política. Ed. Jorge Tula. Trad. Jorge Tula y otros. México D.F.: Siglo XXI, 2016. 3-7.

Rojas, Manuel. Tiempo irremediable. Mecanoscrito inédito. 1950. Biblioteca Nacional de Chile. Archivo del escritor. 000858731. http://www.memoriachilena.gob.cl/602/w3article-348589.html.

Tiempo irremediable. Mecanoscrito inédito. 1951. Biblioteca Nacional de Chile. 000909215. http://www.memoriachilena.gob.cl/602/w3-article-341634.html.

Hijo de ladrón. Santiago: Zig-Zag, 1958.

"Variedades de lumpen”. Páginas excluidas. Ed. Federico Schopf. Santiago: Universitaria, 1997. 266-268.

“Algo sobre Hijo de ladrón". Hijo de ladrón. Edición establecida por David Barrera, Diego Leiva, Alejandra Caballero e Ignacio Álvarez. Santiago: Tajamar Editores, 2018. 361-390.

Hijo de ladrón. Edición establecida por David Barrera, Diego Leiva, Alejandra Caballero e Ignacio Álvarez. Santiago: Tajamar Editores, 2018.

Ubilla Espinoza, Lorena. "Sujetos marginales en la narrativa de Manuel Rojas: de disciplinamientos a focos de tensión con el proceso modernizador". Revista Chilena de Literatura 77 (2010). Web. 